\title{
Correction: Santos, R.S., et al. Improvement of IFN $\gamma$ ELISPOT Performance Following Overnight Resting of Frozen PBMC Samples Confirmed Through Rigorous Statistical Analysis. Cells 2015, 4, 1-18
}

\section{Radleigh Santos ${ }^{1}$, Alcinette Buying ${ }^{2}$, Nazila Sabri ${ }^{2}$, John Yu ${ }^{3,4}$, Anthony Gringeri ${ }^{4}$, James Bender ${ }^{4, \dagger}$, Sylvia Janetzki ${ }^{5}$, Clemencia Pinilla ${ }^{2, *}$ and Valeria A. Judkowski ${ }^{2, *}$}

1 Torrey Pines Institute for Molecular Studies, 11350 SW Village Parkway Port St. Lucie, FL 34987, USA; E-Mail: rsantos@tpims.org

2 Torrey Pines Institute for Molecular Studies, 3550 General Atomics Court, San Diego, CA 92121, USA; E-Mails: abunying@tpims.org (A.B); nsabri@tpims.org (N.S)

3 Cedars-Sinai, 8700 Beverly Blvd., Los Angeles, CA 90048, USA; E-Mail: John.Yu@cshs.org

4 ImmunoCellular Therapeutics Ltd., 23622 Calabasas Road, Calabasas, CA 91302, USA; E-Mails: anthony.gringeri@imuc.com (A.G.); james.bender@lionbio.com (J.B.)

5 ZellNet Consulting, 555 North Ave., Fort Lee, NJ 07024, USA; E-Mail: sylvia@zellnet.com

$\dagger$ Present address: Lion biotechnologies, 21900 Burbank Blvd., Woodland Hills, CA 91367, USA.

* Authors to whom correspondence should be addressed; E-Mails: pinilla@tpims.org (C.P.); vjudkowski@tpims.org (V.A.J.); Tel./Fax: +1-858-597-3883 (C.P.); +1-858-597-3869 (V.A.J.).

Academic Editor: Alexander E. Kalyuzhny

Received: 16 April 2015 / Accepted: 20 April 2015 / Published: 21 April 2015

The authors wish to make the following corrections to this paper [1]:

In Section 2.3 ELISPOT Assay, on page 4, the following text is missing: "PBMC samples from each donor were tested after three different resting time points $(0,18,22 \mathrm{~h}$.) for their reactivity to a pool of 5 HLA-A2.1-restricted viral peptides from influenza (Inf) virus, EBV and HCMV (A2-CEF) or to each of the A2-CEF peptides individually. TRP-2, a tumor-associated antigen, was also included as a control. The A2-CEF peptide pool or each of the peptides was tested in triplicate. Background controls (no peptide added) were tested by six replicates. See the workflow overview in Figure 1. PVDF 96-well plates (MSIPS4510, Millipore, Darmstadt, Germany) were pre-wetted with $15 \mu \mathrm{L}$ per well of $70 \%$ ethanol and shaken with a plate shaker for 15 seconds. Each plate was then washed three 
times with PBS without $\mathrm{Ca} / \mathrm{Mg}$ (Hyclone, Waltham, Massachusetts). Afterwards, the plates were coated with anti-IFN $\gamma$ antibody (Clone 1-D1k, Mabtech, Cincinnati, OH) at $100 \mu \mathrm{L}$ per well at a final concentration of $10 \mu \mathrm{g} / \mathrm{mL}$ and wrapped in aluminum foil for ON storage at $4{ }^{\circ} \mathrm{C}$. The following day, the coating antibody was removed by washing with $200 \mu \mathrm{L}$ PBS per well. Plates were blocked with $150 \mu \mathrm{L} /$ well culture medium, for at least one hour and up to $3 \mathrm{~h}$ at $37{ }^{\circ} \mathrm{C}$. The blocking medium was discarded and $50 \mu \mathrm{L}$ of cell suspension (300,000 cells/well) or medium (medium only wells) were added. The plates were placed back in the incubator $\left(37^{\circ} \mathrm{C}, 5 \% \mathrm{CO}_{2}\right)$ for at least one hour for the cells to settle down. Without disturbing the effector cells, an equal volume of medium (as the negative control), phytohemagglutinin (PHA) (Remel, Inc., Waltham, Massachusetts, USA), for a final concentration of $5 \mu \mathrm{g} / \mathrm{mL}$, or antigen, for a final concentration of $5 \mu \mathrm{g} / \mathrm{mL}$ of each peptide, were added to the wells (the A2-CEF peptide pool was obtained from BioSynthesis, Lewisville, TX; individual 9mer peptides from JPT Peptide Technologies, Berlin, Germany; and TRP-2 peptide from PolyPeptide, San Diego, CA, USA); see Figure 1. Plates were wrapped in foil and placed at $37{ }^{\circ} \mathrm{C}$ in a $5 \% \mathrm{CO}_{2}$ humidified incubator for at least $16 \mathrm{~h}$. After incubation, the suspension was removed by flicking, and the plates were washed six times with PBS/0.05\% Tween 20 (P/T20) on a plate washer (Biotek, Winooski, VT). An anti-IFN $\gamma$ biotinylated antibody (Clone 7-B6-1, Mabtech, Cincinnati, OH) solution in $\mathrm{PBS} / 0.5 \%$ BSA with a final concentration of $1 \mu \mathrm{g} / \mathrm{mL}$ was filtered with a $0.2-\mu \mathrm{m}$ low proteinbinding syringe filter (CORNING, Corning, NY) and added at $100 \mu \mathrm{L}$ per well. The plates were wrapped in aluminum foil and returned to the incubator $\left(37{ }^{\circ} \mathrm{C}, 5 \% \mathrm{CO}_{2}\right)$ for $2 \mathrm{~h}$, followed by three washes with P/T20 and the addition of $100 \mu \mathrm{L} /$ well of a streptavidin-HRP (Mabtech, Cincinnati, $\mathrm{OH}$ ) solution prepared according to the manufacturer's instructions. Plates were incubated at room temperature (RT) for $1 \mathrm{~h}$, washed once with P/T20 and twice with PBS only. AEC (3-amino-9ethylcarbazole) substrate (Vector Laboratories, Burlingame, CA) was added at $100 \mu \mathrm{L}$ per well for 3 min, and spot development was stopped with three washes with $\mathrm{dH}_{2} \mathrm{O}$ (distillated water). The underdrain of the plate was removed to wash the back of the plate. The plate membranes were left to dry $\mathrm{ON}$ in the dark at RT in preparation for the evaluation. Figure 1 shows the different experimental conditions and peptides with their corresponding sequences tested in the study."

The authors would like to apologize for any inconvenience caused to the readers by these changes.

\section{Reference}

1. Santos, R.; Buying, A.; Sabri, N.; Yu, J.; Gringeri, A.; Bender, J.; Janetzki, S.; Pinilla, C.; Judkowski, V.A. Improvement of IFN $\gamma$ ELISPOT Performance Following Overnight Resting of Frozen PBMC Samples Confirmed Through Rigorous Statistical Analysis. Cells 2015, 4, 1-18.

(C) 2015 by the authors; licensee MDPI, Basel, Switzerland. This article is an open access article distributed under the terms and conditions of the Creative Commons Attribution license (http://creativecommons.org/licenses/by/4.0/). 